\title{
Costs variations for percutaneous nephrolithotomy in the U.S. from 2003-2015: A contemporary analysis of an all-payer discharge database
}

Jeffrey J. Leow, MBBS, MPH ${ }^{* 1,2}$; Anne-Sophie Valiquette, $\mathrm{MD}^{* 3}$; Benjamin I. Chung, MD ${ }^{4}$;

Steven L. Chang, MD, MS ${ }^{1,5}$; Quoc-Dien Trinh, MD ${ }^{1,5}$; Rus Korets, MD ${ }^{6}$; Naeem Bhojani, MD $^{3}$ ${ }^{*}$ Co-first authors

${ }^{1}$ Division of Urology and Centre for Surgery and Public Health, Brigham and Women’s Hospital, Harvard Medical School, Boston, MA, United States; ${ }^{2}$ Department of Urology, Tan Tock Seng Hospital, Singapore; ${ }^{3}$ Department of Urology, Université de Montréal, Montreal, QC, Canada; ${ }^{4}$ Department of Urology, Stanford University, Stanford, CA, United States; ${ }^{5}$ Lank Centre for Genitourinary Oncology, Dana-Farber/Brigham and Women’s Cancer Centre, Harvard Medical School, Boston, MA, United States; ${ }^{6}$ Veterans Affairs Boston Healthcare System, Harvard Medical School, Boston, MA, United States

Cite as: Can Urol Assoc J 2018 June 19; Epub ahead of print. http://dx.doi.org/10.5489/cuaj.5280

\section{Published online June 19, 2018}

$* * *$

\section{Abstract}

Introduction: We sought to evaluate population-based costs variations and predictors of outlier costs for percutaneous nephrolithotomy (PCNL) in the U.S.

Methods: Using the Premier Healthcare Database, we identified all patients diagnosed with kidney/ureter calculus who underwent PCNL from 2003-2015. We evaluated 90-day direct hospital costs, defining high- and low-cost surgery as those $>90$ th and $<10$ th percentile, respectively. We constructed a multilevel, hierarchical regression model and calculated the pseudo- $\mathrm{R}^{2}$ of each variable, which translates to the percentage variability contributed by that variable on 90-day direct hospital costs.

Results: A total of 114581 patients underwent PCNL during the 12-year study period. Mean cost in the low-cost group was \$5787 (95\% confidence interval [CI] 5716-5856) vs. \$38 590 (95\% CI 37 357-39 923) in the high-cost group. Cost variations were substantially impacted by patient (63.7\%) and surgical (18.5\%) characteristics and less so by hospital characteristics (3.9\%). Significant predictors of high costs included more comorbidities ( $\geq 2$ vs. 0 : odds ratio [OR] 1.81; $\mathrm{p}=0.01$ ) and hospital region (Northeast vs. Midwest: OR 2.04; $\mathrm{p}=0.03$ ). Predictors of low cost were hospital bed size of 300-499 beds (OR 1.35; $\mathrm{p}<0.01$ ) and urban hospitals (OR 2.77; $\mathrm{p}=0.01$ ). Factors less likely to be associated with low-cost PCNL were more comorbidities (Charlson Comorbidity Index $[\mathrm{CCI}] \geq 2$ : OR 0.69; $<<0.0001$ ), larger hospitals (OR 0.61; $\mathrm{p}=0.01$ ), and teaching hospitals (OR 0.33; $\mathrm{p}<0.0001$ ). 
Conclusions: Our contemporary analysis demonstrates that patient and surgical characteristics had a significant effect on costs associated with PCNL. Poor comorbidity status contributed to high costs, highlighting the importance of patient selection.

\section{Introduction}

About $10 \%$ of the American population is affected by kidney stones. ${ }^{1}$ Stone disease, due to its high prevalence, high rate of recurrence, frequent need for surgical management and impact on work absenteeism, has important economic repercussions. In the United States, stone disease is associated with an annual cost greater than 2 billion dollars. ${ }^{2}$ Various surgical interventions can be undertaken for the management of stone disease, namely SWL, URS and PCNL. According to the most recent AUA guidelines, PCNL is indicated as first-line therapy for symptomatic patients with a total renal stone burden larger than $2 \mathrm{~cm}^{3}{ }^{3}$ PCNL represents about $5 \%$ of stone procedures. ${ }^{2}$ It is associated with the highest stone free rate, but represents a more complex surgery with a steeper learning curve and higher complication rates, compared to the other procedures. ${ }^{4}$ Given its potential morbidity, there has been interest to examine variations in care and outcomes. High-volume academic centers may perform better with decreased morbidity and higher stone-free rates, but it is unclear whether this is secondary to better surgeon technique, volume, or processes of care, and whether these ultimately translate to cost differences. A comprehensive population-level assessment of PCNL costs has not been performed. Therefore, we performed a study examining 90-day direct line-item hospital costs post-PCNL, hypothesizing that there exists substantial cost variation across surgeons and hospitals.

\section{Methods}

\section{Data source}

The Premier Healthcare Database (Premier, Inc., Charlotte, NC), a nationally representative allpayer claims database, represents $>75$ million inpatient discharges, including $~ 20 \%$ of all hospitalizations at $>700$ hospitals in the US. This claims-based database provides billing information via ICD-9 codes, and standardized billing items including direct item costs for most hospitalizations (e.g. medications, laboratory services, room and board, etc). ICD-9 codes were used to identify patients' diagnoses and procedures. As data are anonymized and HIPAAcompliant data, institutional review board waiver was obtained.

Hospital-specific projection weights are applied to each discharge. This allows for the projection of the sample to a national estimate of inpatient discharges. The projection

methodology was developed by Premier and validated by the FDA. ${ }^{5}$ Hospital-level projection weights are then applied to each discharge; all numbers reported herein refer to the weighted estimates.

\section{Study population}

Using ICD-9 codes, we identified individuals diagnosed with kidney or ureteric calculus (592.0, 
592.1, 592.9) who underwent PCNL (55.04 or 55.03 with 55.21) between January 1, 2003 and December 31, 2015. Patients treated with PCNL were identified as previously described, using ICD-9 procedural codes 55.04 for percutaneous nephrostomy with fragmentation and 55.03 for percutaneous nephrostomy combined with 55.21 for nephroscopy. ${ }^{6,7}$

Our weighted cohort consisted of 236,999 individuals who underwent PCNL by 3,531 surgeons at 458 unique hospitals. After excluding surgeons whose annual surgical volume is $<3$ PCNL, which is likely too small to perform a meaningful analysis (median annual surgeon volume was 3; $75^{\text {th }}$ percentile: $6,90^{\text {th }}$ percentile: 12 ), our final cohort had 114,581 patients who underwent PCNL by 911 unique surgeons at 301 different hospitals in the US.

\section{Study variables}

Our outcome of interest was direct hospital costs, including that of the entire procedure, inpatient stay and/or readmissions up to 90-day postoperatively. Costs were adjusted to 2016 US dollars using the medical component of the Consumer Price Index.

We examined relevant patient, hospital, and surgical characteristics. Patient characteristics included age, race, marital status, insurance status, and CCI. ${ }^{8}$ Hospital characteristics included teaching status, urbanicity, bedsize, hospital annual PCNL volume (high defined as $>75$ th percentile; $>24$ /year), and US geographic region. Surgical characteristics included surgeon annual PCNL volume (defined as $>75$ th percentile; $>9$ /year), and year of surgery.

\section{Statistical analyses}

First, we sought to identify the scale of variation in non-adjusted direct hospital costs for all attending surgeons who performed $\geq 3$ PCNL/year. To do this, we generated a ranked list of all providers (911 surgeons or 301 hospitals) ordered by 90-day direct hospital costs. Mean costs per provider were calculated by dividing the total direct hospital costs by the number of PCNLs performed by each provider across the study period. This yielded each provider's mean costs per PCNL, along with standard deviations (SD) and 95\% confidence intervals. This was then plotted according to each provider's rank from least to costliest (Online Supplement Figure 1a/b).

Second, to assess for the relative contribution of patient-, hospital- and surgical-level variables on costs, we constructed a multilevel hierarchical regression model and calculated the pseudo- $\mathrm{R}^{2}$ of each variable, which translates to its contribution to costs variability (\%).

Finally, we assessed predictors of high- and low-cost PCNLs, defined as those costing the most $\left(>90^{\text {th }}\right.$ percentile: $\left.\$ 23,615\right)$ and least $\left(<10^{\text {th }}\right.$ percentile: $\left.\$ 6,511\right)$ per PCNL. Summary statistics were constructed using frequencies and proportions for categorical variables, as well as medians and interquartile ranges for continuous variables. Categorical values were compared using chi-square, and continuous variables were compared with the Mann-Whitney test. Subsequently, we developed a multivariate logistic regression model controlling for all aforementioned covariates in order to assess for independent predictors of low and high costs. 
There was no statistically significant collinearity among the covariates. All statistical analyses were performed using STATA 13 (College Station, TX) and SAS 9.3 (SAS Institute, NC). All tests were two-sided and a p-value of $<0.05$ was considered statistically significant.

\section{Results}

We identified a total of 114,581 patients who underwent PCNL, performed by 911 unique surgeons at 301 different hospitals in the US from 2003 to 2015. Baseline cohort characteristics are listed in Table 1. The mean 90-day direct hospital costs for each PCNL patient was $\$ 14,498$ (SE \$83) and the median cost was \$11,930 (IQR: \$9,016-\$16,517). The lowest decile of costs $(<\$ 6,511)$ consisted of 405 surgeons at 194 hospitals with a mean cost per PCNL of $\$ 4,968$ (SE $\$ 52)$, while the top decile of costs $(>\$ 23,615)$ consisted of 269 surgeons at 147 hospitals with a mean cost per PCNL of \$36,061 (SE \$435). There was over a 7-fold difference in mean costs between the least and costliest groups. Mean costs per surgeon and hospital were ranked in ascending order and plotted along with 95\% CI (Online Supplement Figures 1a/b. Overall, annual mean cost per PCNL remained stable over the period of the study (Online Supplement Figure 2). Costs breakdowns by category are shown in Figure 1, and further sub-divided into high-cost vs. low-cost PCNL and high volume vs. low volume surgeons. We found that the room and board costs and operating room costs were higher among the high-cost PCNLs compared to the low-cost PCNLs. This was confirmed to be true when the mean length of stay of the highcost PCNLs was 8.79 days compared to 2.83 days among the low-cost PCNLs $(\mathrm{p}<0.00)$.

Our multilevel hierarchical regression pseudo- $\mathrm{R}^{2}$ model showed that patient characteristics greatly contributed to variations in costs (63.7\%). CCI had an important impact on cost variation (41.1\%), similar to insurance status (39.3 \%). Concerning surgeon characteristics, surgical volume was the most important contributor to variability in PCNL costs (15.8\%) (Table 2).

On multivariable logistic regression, we identified several patient, surgical and hospital characteristics, which predicted high- (Table 3a) and low- (Table 3b) cost surgeries.

Predictors of high-cost PCNL

Patients with a poorer health status, classified as $\mathrm{CCI} \geq 2$, were more likely to have a higher cost PCNL (CCI $\geq 2$ vs CCI=0; OR 1,81, p=0.01). Performing PCNL in a hospital located in Northeast USA was also a predictor of a higher cost surgery. (Northeast vs. Midwest, OR 2.04, $\mathrm{p}=0.03$ ). On the other hand, patients with private insurance were less likely to have a higher cost PCNL procedure (private vs. Medicare; OR 0.41, $\mathrm{p}=0.01$ ).

Predictors of low-cost PCNL

Middle-sized hospital (300-499 vs. <300 beds; OR 1.35, $<<0.0001)$ and urban medical centers (rural vs urban, OR 2.77, $\mathrm{p}=0.01$ ) were both predictors of low cost PCNL. Once again, our analysis showed that poorer health status had an impact on PCNL costs. In fact, patients with a CCI of 1 (CCI 0 vs CCI 1, OR 0.85, p=0.01) and CCI $\geq 2$ (CCI 0 vs CCI $\geq 2$, OR 0.69, p<0.0001) 
were less likely to undergo low cost PCNL. Patients operated in a teaching hospital were approximately threefold less likely to have a PCNL in the low cost group (non-teaching vs teaching hospital, OR 0.33, $\mathrm{p}<0.0001$ ).

\section{Discussion}

Due to the high prevalence of kidney stones and the increasing costs associated with its management, ${ }^{2}$ we decided to examine variations in PCNL costs and contemporary predictors of high- and low-cost PCNL procedures. We first determined that mean cost of PCNL has remained stable throughout the study period (2003 to 2015). Second, we identified patient health status, classified by CCI, type of health insurance and surgeon's experience (defined by annual surgical volume), as significant factors contributing to the cost variation of PCNL. Using multivariable logistic regression, we examined the predictors of high and low cost PCNL procedures. Results demonstrated that patients with a CCI $\geq 2$ and those treated in the Northeast part of the USA were more likely to undergo high cost PCNL. On the other hand, privately insured patients had lower odds of incurring high cost PCNL. Predictors of low-cost PCNLs were identified as being middle-sized hospitals (300-499 beds) and urban medical centers. However, patients with a CCI $\geq 1$ and those who underwent PCNL in a teaching hospital were less likely to be part of the lowcost group. Several of these results require further comment.

First, our results demonstrate that the mean cost of PCNL has not changed in over 10 years. This is interesting since technological advancements and stone complexity have changed over the study period however, it would seem that the impact is minimal. That said, there exists a large variability between the low- $(\$ 6,511)$ and high-cost PCNLs $(\$ 23,615)$.

Second, our results showed that in addition to contributing significantly to cost variation of PCNL, poor health status $(\mathrm{CCI} \geq 2)$ was a predictor of high cost surgery, and a negative predictor of low-cost PCNL. As is the case with most types of surgery, increased treatment costs are mainly secondary to complications which can lead to a prolonged length of hospital stay (LOS). This appears to be true in our cohort of patients where we found that higher room and board costs (owing to longer hospitalization) was a main driver of higher costs. Various studies have examined the predictors of outcomes post-PCNL. Comorbidities and poor health status have been identified as common predictors of poor outcomes following PCNL. ${ }^{8-14}$ Labate et al. reported a $20.5 \%$ post-PCNL complication rate, with health status (defined using the ASA classification) and operative time being the two main predictors of poor outcomes. ${ }^{12}$ Similar results were confirmed in three recent studies, which demonstrated that a higher CCI score was correlated with increasing odds of severe complications and prolonged LOS following PCNL $^{8,13,14}$. Similar to our study (median PCNL costs of $\$ 11,930$ (Q1 to Q3: $\$ 9.016$ to $\$ 16,517$ ), PCNL median cost has been shown to be variable in different studies, ranging from around $\$ 5,000$ to $\$ 25,000$ per PCNL. ${ }^{15-17}$ A study by Bagrodia et al. showed the different components of direct cost per PCNL and identified operating room services, surgical supplies and room costs as the most important contributors to direct expenditures. ${ }^{15}$ Patients with multiple comorbidities 
tend to have longer LOS and operative time, hence increases in direct costs associated with their procedure. To our knowledge, Bagrodia's study is the only other study available looking at the predictors of cost of PCNL. Interestingly, the only predictor of higher cost which they identified on multivariable analysis was stone burden; there was no correlation between patient characteristics and PCNL cost. ${ }^{15}$ This may be secondary to a different health status classification (ASA vs. CCI), and their small cohort of 200 patients from a single academic teaching hospital. In contrast, our population-based cohort of over 114,000 patients represents a variety of hospital settings (teaching status, bed size, urban city, and geographic region). Our results are important for the urologic community especially in this era of high medical cost and budgetary constraints. This study underlines the importance of careful patient selection and if possible, modifications in patient habits pre-operatively to make them more suitable for surgery. ${ }^{9}$

PCNL is the most complex intervention related to kidney stone management. Its steep learning curve has been examined in various studies. It has been demonstrated that 60 PCNL is the cut-off for the performance of a safe procedure. ${ }^{18-21}$ It has also been established that highvolume centers and surgeons have better outcomes post-PCNL. ${ }^{11,22-24}$ Opondo et al. demonstrated that after adjusting for patient and stone characteristics, high-volume centers had lower complication rates and shorter LOS. ${ }^{22}$ Similarly, another study showed that for identical procedures, high-volume surgeons had significantly better outcomes than less experienced colleagues. However, high-volume surgeons in general had the same complication rates as their less experienced colleagues, because of the more complex cases they had to perform. Highvolume surgeons and high-volume/tertiary hospitals receive transfers from general urologists to perform complex PCNL cases. ${ }^{15,22,25}$ These include cases with substantial stone burden, staghorn calculi and anatomic abnormalities. ${ }^{26,27}$ Even in the hands of experts, such cases associated with increased rates of complications, need for multiple punctures, longer operative times, longer LOS and need for secondary procedures. These complexity factors have been associated with increased cost of PCNL. ${ }^{15}$ High-volume hospitals where high-volume surgeons work often are teaching hospitals. It can be hypothesized that these teaching hospitals have a higher propensity of complex cases being referred to them. It is also probable that in these centers, the implication of trainees can lead to even longer operative times and higher rates of complications, as they have not completed their learning curve. ${ }^{22}$ This may explain the negative correlation between teaching hospitals and low-cost PCNL we found in our study. However, when adjusting for case complexity, Huang and colleagues found that high volume surgeons had lower cost related to PCNL, mainly because of shorter LOS and lower intensive care unit transfers. ${ }^{28}$ Our study did not identify surgeon or hospital volume as predictors of low- or high-cost PCNLs. It however showed that surgeon volume was a predictor of cost variability. This absence of correlation could be explained by the lack of stone characteristics in our analysis; hence adjustments for cases complexity could not be ascertained from our database. Finally, the cut-off we established for 
surgical volume was annual and not total, which probably does not adequately represent the surgeon's true experience.

Despite strengths, our study is not devoid of limitations. Firstly, there may be residual differences at the hospital-by-hospital level or even at the surgeon-by-surgeon level in cost estimation, which may contribute to some of the observed variations in costs. Secondly, as with any secondary analysis of an administrative database, it may be prone to coding errors leading to misclassification bias. Thirdly, the retrospective design of our study subjects it to selection bias and unmeasured variables such as prior surgery, ${ }^{29}$ obesity, ${ }^{30-32}$ stone complexity, ${ }^{33}$ burden, location of calculi, number of punctures, ${ }^{34}$ approach (supine/prone) ${ }^{35}$, exit strategy (tube or tubeless $)^{36}$, and need for secondary procedures, which may impact outcomes and costs. Fourthly, we were only able to capture inpatient hospitalization requiring at least 1 night of hospital stay. Therefore, we were unable to determine which patients had a secondary procedure after PCNL, e.g. SWL, or URS done typically as a day surgery procedure. This has implications on the estimation of the true cost of PCNL.

Finally, in our estimation of individual surgeons' volume, we were only able to calculate the number of operations performed within the Premier hospital network. Thus, some surgeons who perform surgery at both Premier and non-Premier hospitals may have a higher true surgical volume than that reflected in our analysis.

\section{Conclusion}

Percutaneous nephrolithotomy is considered the most invasive, complex and costly stone procedure in the endoscopy era of stone management. Its cost is influenced mainly by patient and surgeon characteristics. We identified that the main predictor of high cost is patient's poor health status. It is an important reminder that surgeons need to carefully select their patients for surgery, as much for patient safety as well as from a socio-economic point of view. 


\section{References}

1. Stamatelou KK, Francis ME, Jones CA, Nyberg LM, Curhan GC. Time trends in reported prevalence of kidney stones in the United States: 1976-1994. Kidney Int 2003; 63(5): 1817-23.

2. Pearle MS, Calhoun EA, Curhan GC, Urologic Diseases of America P. Urologic diseases in America project: urolithiasis. J Urol 2005; 173(3): 848-57.

3. Assimos D, Krambeck A, Miller NL, et al. Surgical Management of Stones: American Urological Association/Endourological Society Guideline, PART I. The Journal of urology 2016; 196(4): 1153-60.

4. El Tayeb MM, Knoedler JJ, Krambeck AE, Paonessa JE, Mellon MJ, Lingeman JE. Vascular complications after percutaneous nephrolithotomy: 10 years of experience. Urology 2015; 85(4): 777-81.

5. Premier. Premier Healthcare Database Whitepaper: Data that Informs and Performs. 2017. https://www.premierinc.com/transforming-healthcare/healthcare-performanceimprovement/premier-research-services/ (accessed April 5 2017).

6. Leow JJ, Meyer CP, Wang Y, et al. Contemporary Trends in Utilization and Perioperative Outcomes of Percutaneous Nephrolithotomy in the United States from 2003 to 2014. Journal of endourology / Endourological Society 2017; 31(8): 742-50.

7. Speed JM, Wang Y, Leow JJ, et al. The Effect of Physician Specialty Obtaining Access for Percutaneous Nephrolithotomy on Perioperative Costs and Outcomes. Journal of endourology / Endourological Society 2017; 31(11): 1152-6.

8. Unsal A, Resorlu B, Atmaca AF, et al. Prediction of morbidity and mortality after percutaneous nephrolithotomy by using the Charlson Comorbidity Index. Urology 2012; 79(1): 55-60.

9. Michel MS, Trojan L, Rassweiler JJ. Complications in percutaneous nephrolithotomy. European urology 2007; 51(4): 899-906; discussion

10. Olvera-Posada D, Tailly T, Alenezi H, et al. Risk Factors for Postoperative Complications of Percutaneous Nephrolithotomy at a Tertiary Referral Center. J Urol 2015; 194(6): 1646-51.

11. Seitz C, Desai M, Hacker A, et al. Incidence, prevention, and management of complications following percutaneous nephrolitholapaxy. Eur Urol 2012; 61(1): 146-58.

12. Labate G, Modi P, Timoney A, et al. The percutaneous nephrolithotomy global study: classification of complications. J Endourol 2011; 25(8): 1275-80.

13. Kadlec AO, Ellimoottil C, Guo R, Trinh QD, Sun M, Turk TM. Contemporary volumeoutcome relationships for percutaneous nephrolithotomy: results from the Nationwide Inpatient Sample. J Endourol 2013; 27(9): 1107-13. 
14. Moreno-Palacios J, Maldonado-Alcaraz E, Montoya-Martinez G, et al. Prognostic factors of morbidity in patients undergoing percutaneous nephrolithotomy. J Endourol 2014; 28(9): 1078-84.

15. Bagrodia A, Gupta A, Raman JD, Bensalah K, Pearle MS, Lotan Y. Predictors of cost and clinical outcomes of percutaneous nephrostolithotomy. The Journal of urology 2009; 182(2): 586-90.

16. Lotan Y, Pearle MS. Economics of stone management. The Urologic clinics of North America 2007; 34(3): 443-53.

17. Hyams ES, Shah O. Percutaneous nephrostolithotomy versus flexible ureteroscopy/holmium laser lithotripsy: cost and outcome analysis. J Urol 2009; 182(3): 1012-7.

18. Tanriverdi O, Boylu U, Kendirci M, Kadihasanoglu M, Horasanli K, Miroglu C. The learning curve in the training of percutaneous nephrolithotomy. Eur Urol 2007; 52(1): 206-11.

19. Ziaee SA, Sichani MM, Kashi AH, Samzadeh M. Evaluation of the learning curve for percutaneous nephrolithotomy. Urol J 2010; 7(4): 226-31.

20. Schilling D, Gakis G, Walcher U, Stenzl A, Nagele U. The learning curve in minimally invasive percutaneous nephrolitholapaxy: a 1-year retrospective evaluation of a novice and an expert. World J Urol 2011; 29(6): 749-53.

21. de la Rosette JJ, Laguna MP, Rassweiler JJ, Conort P. Training in percutaneous nephrolithotomy--a critical review. Eur Urol 2008; 54(5): 994-1001.

22. Opondo D, Tefekli A, Esen T, et al. Impact of case volumes on the outcomes of percutaneous nephrolithotomy. European urology 2012; 62(6): 1181-7.

23. de la Rosette JJ, Zuazu JR, Tsakiris P, et al. Prognostic factors and percutaneous nephrolithotomy morbidity: a multivariate analysis of a contemporary series using the Clavien classification. The Journal of urology 2008; 180(6): 2489-93.

24. el-Nahas AR, Eraky I, Shokeir AA, et al. Factors affecting stone-free rate and complications of percutaneous nephrolithotomy for treatment of staghorn stone. Urology 2012; 79(6): 1236-41.

25. e la Rosette J, Assimos D, Desai M, et al. The Clinical Research Office of the Endourological Society Percutaneous Nephrolithotomy Global Study: indications, complications, and outcomes in 5803 patients. J Endourol 2011; 25(1): 11-7.

26. Dauw CA, Borofsky MS, York N, Lingeman JE. Percutaneous Nephrolithotomy in the Superobese: A Comparison of Outcomes Based on Body Mass Index. Journal of endourology / Endourological Society 2016; 30(9): 987-91.

27. Violette PD, Dion M, Tailly T, Denstedt JD, Razvi H. Percutaneous nephrolithotomy in patients with urinary tract abnormalities. Journal of endourology / Endourological Society 2014; 28(12): 1448-54. 
28. Huang WY, Wu SC, Chen YF, Lan CF, Hsieh JT, Huang KH. Surgeon volume for percutaneous nephrolithotomy is associated with medical costs and length of hospital stay: a nationwide population-based study in Taiwan. Journal of endourology / Endourological Society 2014; 28(8): 915-21.

29. Ozgor F, Kucuktopcu O, Ucpinar B, et al. The effects of previous open renal stone surgery types on PNL outcomes. Canadian Urological Association journal = Journal de l'Association des urologues du Canada 2016; 10(7-8): E246-E50.

30. Fuller A, Razvi H, Denstedt JD, et al. The clinical research office of the endourological society percutaneous nephrolithotomy global study: Outcomes in the morbidly obese patient - a case control analysis. Canadian Urological Association journal = Journal de l'Association des urologues du Canada 2014; 8(5-6): E393-7.

31. Cakmak O, Tarhan H, Cimen S, et al. The effect of abdominal fat parameters on percutaneous nephrolithotomy success. Canadian Urological Association journal = Journal de l'Association des urologues du Canada 2016; 10(3-4): E99-E103.

32. Alyami FA, Skinner TA, Norman RW. Impact of body mass index on clinical outcomes associated with percutaneous nephrolithotomy. Canadian Urological Association journal = Journal de l'Association des urologues du Canada 2013; 7(3-4): E197-201.

33. Noureldin YA, Elkoushy MA, Andonian S. External validation of the S.T.O.N.E. nephrolithometry scoring system. Canadian Urological Association journal $=$ Journal de l'Association des urologues du Canada 2015; 9(5-6): 190-5.

34. Falahatkar S, Kazemnezhad E, Moghaddam KG, et al. Middle calyx access in complete supine percutaneous nephrolithotomy. Canadian Urological Association journal = Journal de l'Association des urologues du Canada 2013; 7(5-6): E306-10.

35. Falahatkar S, Moghaddam KG, Kazemnezhad E, et al. Factors affecting complications according to the modified Clavien classification in complete supine percutaneous nephrolithotomy. Canadian Urological Association journal = Journal de l'Association des urologues du Canada 2015; 9(1-2): e83-92.

36. 36. Beiko D, Lee L. Outpatient tubeless percutaneous nephrolithotomy: the initial case series. Canadian Urological Association journal $=$ Journal de l'Association des urologues du Canada 2010; 4(4): E86-90. 
Figures and Tables

Fig. 1. Breakdown of 90-day direct hospital costs for percutaneous nephrolithotomy (PCNL) in the U.S. from 2003-2015.

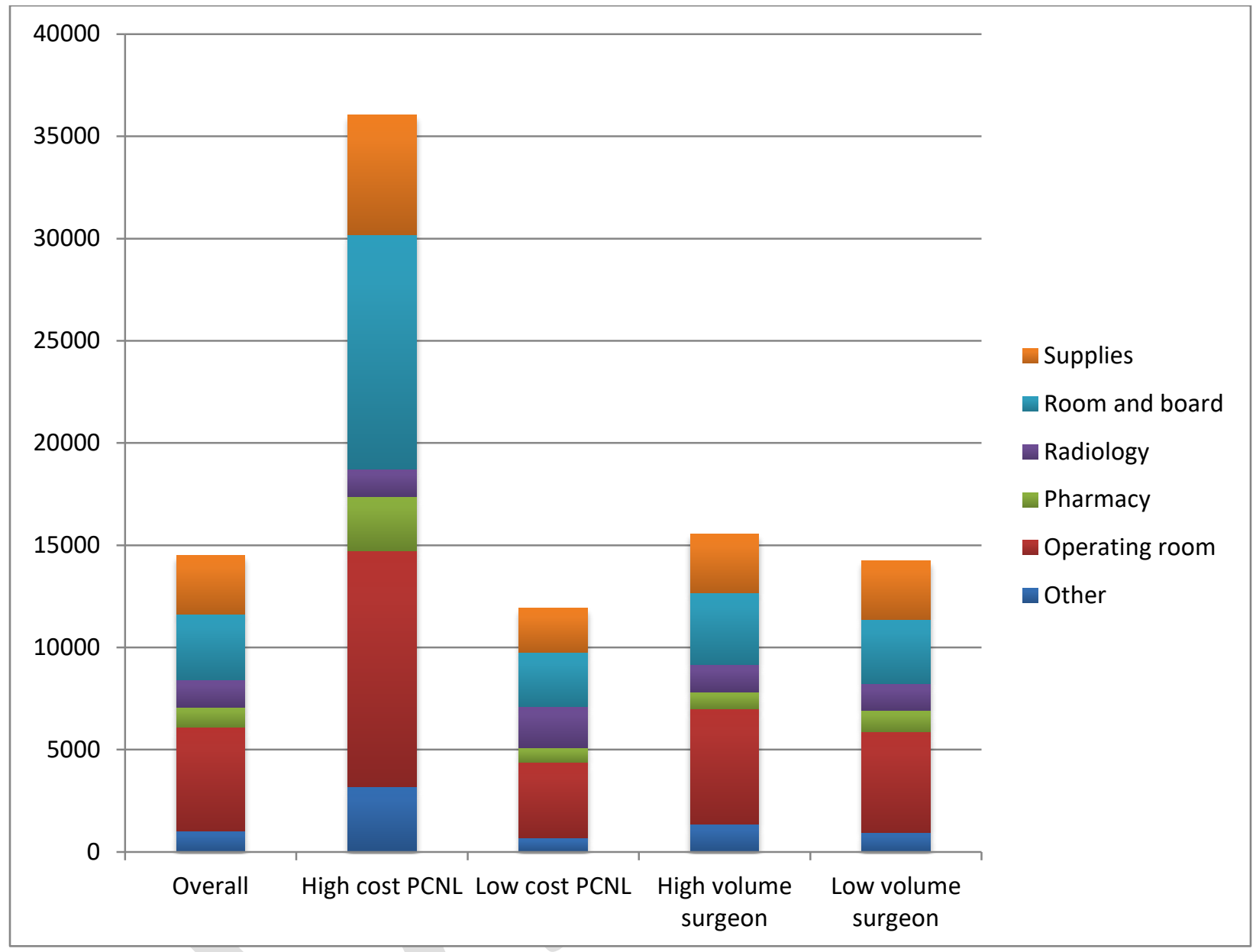




\begin{tabular}{|c|c|c|c|}
\hline Patient characteristics & Low costs & High costs & $\begin{array}{c}\begin{array}{c}\text { Overall } \\
(\mathrm{n}=114581)\end{array} \\
\end{array}$ \\
\hline Mean age (s.e.) & $53.8(0.5)$ & $54.9(0.38)$ & $54.5(0.1)$ \\
\hline \multicolumn{4}{|l|}{ Gender } \\
\hline Male & $4104(47.7)$ & 5697 (46.6) & $55067(48.1)$ \\
\hline Female & $4498(52.3)$ & $6537(53.4)$ & $59514(51.9)$ \\
\hline \multicolumn{4}{|l|}{ Race } \\
\hline White & $6008(69.8)$ & 9040 (73.9) & $86751(75.7)$ \\
\hline Non-White & $2595(30.2)$ & 3195 (26.1) & $27831(24.3)$ \\
\hline \multicolumn{4}{|l|}{ Marital status } \\
\hline Married & $3302(38.4)$ & 4825 (39.4) & $49035(42.8)$ \\
\hline Non-married & $5300(61.6)$ & $7410(60.6)$ & $65546(57.2)$ \\
\hline \multicolumn{4}{|l|}{ Insurance status } \\
\hline Medicare & 3051 (35.5) & $5828(47.6)$ & $45774(39.9)$ \\
\hline Medicaid & 1049 (12.2) & 2355 (19.2) & $14396(12.6)$ \\
\hline Private & 3925 (45.6) & 3618 (29.6) & $46302(40.4)$ \\
\hline Other & $577(6.7)$ & $433(3.5)$ & $8109(7.1)$ \\
\hline \multicolumn{4}{|c|}{ Charlson Comorbidity Index } \\
\hline 0 & $4721(54.9)$ & 4642 (37.9) & $55053(48.0)$ \\
\hline 1 & $2124(24.7)$ & $2946(24.1)$ & $28830(25.2)$ \\
\hline$\geq 2$ & $1757(20.4)$ & $4646(38.0)$ & $30698(26.8)$ \\
\hline \multicolumn{4}{|l|}{ Hospital characteristics } \\
\hline \multicolumn{4}{|l|}{ Hospital teaching status } \\
\hline Teaching & $1524(62.6)$ & $7135(58.3)$ & $67170(58.6)$ \\
\hline Non-teaching & $7079(82.3)$ & 5099 (41.7) & $47411(41.4)$ \\
\hline \multicolumn{4}{|l|}{ Hospital bed size } \\
\hline$<300$ beds & $1946(22.6)$ & $2370(19.4)$ & $27409(23.9)$ \\
\hline 300-499 beds & 4797 (55.8) & 4199 (34.3) & $47280(41.3)$ \\
\hline$\geq 500$ beds & 1859 (21.6) & 5665 (46.3) & $39892(34.8)$ \\
\hline \multicolumn{4}{|l|}{ Hospital location } \\
\hline Urban & $8468(98.4)$ & $11867(97.0)$ & 111056 (96.9) \\
\hline Rural & $135(1.6)$ & $367(60.3)$ & 3526 (3.1) \\
\hline
\end{tabular}




\begin{tabular}{|l|c|c|c|}
\hline Midwest & $1063(12.4)$ & $2029(16.6)$ & $22764(19.9)$ \\
\hline Northeast & $1107(12.9)$ & $5208(42.6)$ & $26305(22.9)$ \\
\hline South & $5306(61.7)$ & $3468(28.3)$ & $26305(43.1)$ \\
\hline West & $1126(13.1)$ & $1529(12.5)$ & $26305(14.1)$ \\
\hline Hospital volume & & & \\
\hline$\leq 75$ th percentile ( $\leq 19 / \mathrm{yr})$ & $7612(88.5)$ & $7614(62.2)$ & $92254(80.5)$ \\
\hline$>75$ th percentile $(>19 / \mathrm{yr})$ & $990(11.5)$ & $4621(37.8)$ & $22327(19.5)$ \\
\hline Surgical characteristics & & & \\
\hline Surgeon volume & & & \\
\hline$\leq 75$ th percentile $(\leq 6 / \mathrm{yr})$ & $6838(79.5)$ & $7531(61.6)$ & $92555(80.8)$ \\
\hline$>75$ th percentile $(>6 / y r)$ & $1764(20.5)$ & $4703(38.4)$ & $22027(19.2)$ \\
\hline Year of surgery & & & \\
\hline 2003-2006 & $2736(31.8)$ & $2814(23.0)$ & $30698(26.8)$ \\
\hline 2007-2010 & $2673(31.1)$ & $4569(37.3)$ & $37449(32.7)$ \\
\hline 2011-2015 & $3193(37.1)$ & $4852(39.7)$ & $46434(40.5)$ \\
\hline
\end{tabular}

\begin{tabular}{|c|c|}
\hline $\begin{array}{l}\text { Table 2. Contribution of patient, hospital, and surgical } \\
\text { characteristics of postoperative outcomes to variability in } \\
\text { costs of percutaneous nephrolithotomy (PCNL) }\end{array}$ \\
\hline & $\begin{array}{c}\text { \% variability in } \\
\text { PCNL costs }\end{array}$ \\
\hline Patient characteristics & $63.7 \%$ \\
\hline Age & $4.9 \%$ \\
\hline Gender & $1.9 \%$ \\
\hline Race & $0.9 \%$ \\
\hline Marital status & $1.6 \%$ \\
\hline Insurance status & $39.3 \%$ \\
\hline Charlson Comorbidity Index & $41.1 \%$ \\
\hline Hospital characteristics & $3.9 \%$ \\
\hline Teaching status & $0.3 \%$ \\
\hline Location (urban vs. rural) & $0.0 \%$ \\
\hline Bed size & $0.4 \%$ \\
\hline Region & $1.3 \%$ \\
\hline Annual hospital volume & $1.5 \%$ \\
\hline Surgical characteristics & $18.5 \%$ \\
\hline Annual surgeon volume & $15.8 \%$ \\
\hline Year of surgery & $2.2 \%$ \\
\hline
\end{tabular}


Table 3. Multivariable logistic regression for patient-, sugical-, and hospital-level predictors of (A) high cost ( $>90$ th percentile) and (B) low cost ( $<10$ th percentile) percutaneous nephrolithotomy (PCNL)

\begin{tabular}{|c|c|c|c|c|}
\hline \multirow{2}{*}{$\begin{array}{l}\text { Patient characteristics } \\
\text { Age }\end{array}$} & \multirow{2}{*}{$\frac{\text { Odds ratio }}{0.990}$} & \multicolumn{2}{|c|}{$\begin{array}{c}95 \% \text { confidence } \\
\text { intervals }\end{array}$} & \multirow{2}{*}{$\frac{\mathbf{p}}{0.09}$} \\
\hline & & 0.979 & 1.002 & \\
\hline \multicolumn{5}{|l|}{ Gender } \\
\hline Male & Ref & & & \\
\hline Female & 0.95 & 0.72 & 1.25 & 0.72 \\
\hline \multicolumn{5}{|l|}{ Race } \\
\hline White & Ref & & & \\
\hline Non-White & 0.96 & 0.67 & 1.36 & 0.82 \\
\hline \multicolumn{5}{|l|}{ Marital status } \\
\hline \multicolumn{5}{|l|}{ Married } \\
\hline Non-married & 1.09 & 0.78 & 1.53 & 0.59 \\
\hline \multicolumn{5}{|l|}{ Insurance status } \\
\hline Medicare & Ref & & & \\
\hline Medicaid & 0.96 & 0.52 & 1.79 & 0.90 \\
\hline Private & 0.52 & 0.34 & 0.80 & 0.00 \\
\hline Other & 0.41 & 0.20 & 0.83 & 0.01 \\
\hline \multicolumn{5}{|c|}{ Charlson Comorbidity Index } \\
\hline 0 & Ref & & & \\
\hline 1 & 1.19 & 0.88 & 1.61 & 0.27 \\
\hline$\geq 2$ & 1.81 & 1.18 & 2.79 & 0.01 \\
\hline \multicolumn{5}{|l|}{ Hospital characteristics } \\
\hline \multicolumn{5}{|l|}{ Hospital teaching status } \\
\hline Teaching & 1.39 & 0.86 & 2.24 & 0.18 \\
\hline Non-teaching & Ref & & & \\
\hline \multicolumn{5}{|l|}{ Hospital bed size } \\
\hline$<300$ beds & Ref & & & \\
\hline 300-499 beds & 1.04 & 0.58 & 1.89 & 0.89 \\
\hline$\geq 500$ beds & 1.48 & 0.73 & 3.00 & 0.28 \\
\hline \multicolumn{5}{|l|}{ Hospital location } \\
\hline Urban & 0.75 & 0.24 & 2.36 & 0.63 \\
\hline Rural & Ref & & & \\
\hline Hospital region & & & & \\
\hline
\end{tabular}




\begin{tabular}{|c|c|c|c|c|}
\hline Midwest & Ref & & & \\
\hline Northeast & 2.04 & 1.09 & 3.81 & 0.03 \\
\hline South & 0.79 & 0.39 & 1.59 & 0.51 \\
\hline West & 1.25 & 0.58 & 2.73 & 0.57 \\
\hline \multicolumn{5}{|l|}{ Hospital volume } \\
\hline$\leq 75$ th percentile $(\leq 19 / \mathrm{yr})$ & Ref & & & \\
\hline$>75$ th percentile $(>19 / \mathrm{yr})$ & 0.98 & 0.54 & 1.77 & 0.94 \\
\hline \multicolumn{5}{|l|}{ Surgical characteristics } \\
\hline \multicolumn{5}{|l|}{ Surgeon volume } \\
\hline$\leq 75$ th percentile $(\leq 6 / \mathrm{yr})$ & Ref & & & \\
\hline$>75$ th percentile $(>6 / y r)$ & 1.33 & 0.89 & 1.99 & 0.16 \\
\hline \multicolumn{5}{|l|}{ Year of surgery } \\
\hline $2003-2006$ & Ref & & & \\
\hline $2007-2010$ & 1.40 & 0.86 & 2.28 & 0.18 \\
\hline 2011-2015 & 1.09 & 0.61 & 1.96 & 0.76 \\
\hline \multicolumn{5}{|c|}{ (B) Predictors of low costs for PCNL } \\
\hline Patient characteristics & Odds ratio & $\begin{array}{c}95 \% \\
\text { confidence } \\
\text { intervals }\end{array}$ & $\mathbf{p}$ & \\
\hline Age & 1.003 & 0.987 & 1.020 & 0.682 \\
\hline \multicolumn{5}{|l|}{ Gender } \\
\hline Male & Ref & & & \\
\hline Female & 0.99 & 0.73 & 1.34 & 0.96 \\
\hline \multicolumn{5}{|l|}{ Race } \\
\hline White & Ref & & & \\
\hline Non-White & 0.77 & 0.48 & 1.24 & 0.29 \\
\hline \multicolumn{5}{|l|}{ Marital status } \\
\hline \multicolumn{5}{|l|}{ Married } \\
\hline Non-married & 0.85 & 0.57 & 1.26 & 0.42 \\
\hline \multicolumn{5}{|l|}{ Insurance status } \\
\hline Medicare & Ref & & & \\
\hline Medicaid & 1.39 & 0.68 & 2.84 & 0.37 \\
\hline Private & 1.33 & 0.80 & 2.22 & 0.27 \\
\hline Other & 1.00 & 0.60 & 1.69 & 0.99 \\
\hline \multicolumn{5}{|l|}{ Charlson comorbidity score } \\
\hline 0 & Ref & & & \\
\hline 1 & 0.85 & 0.63 & 1.15 & 0.01 \\
\hline
\end{tabular}




\begin{tabular}{|l|c|c|c|c|}
\hline$\geq 2$ & 0.69 & 0.43 & 1.09 & $<.0001$ \\
\hline Hospital characteristics & & & & \\
\hline Hospital teaching status & & & & \\
\hline Teaching & 0.33 & 0.17 & 0.63 & 0.00 \\
\hline Non-teaching & Ref & & & \\
\hline Hospital bed size & & & & \\
\hline$<300$ beds & Ref & & & \\
\hline 300-499 beds & 1.35 & 1.15 & 1.60 & 0.00 \\
\hline$\geq 500$ beds & 0.61 & 0.49 & 0.75 & $<.0001$ \\
\hline Hospital location & & & & \\
\hline Urban & 2.77 & 1.27 & 6.03 & 0.01 \\
\hline Rural & Ref & & & \\
\hline Hospital region & & & & \\
\hline Midwest & Ref & & & \\
\hline Northeast & 1.54 & 0.53 & 4.44 & 0.42 \\
\hline South & 2.06 & 0.95 & 4.47 & 0.07 \\
\hline West & 1.11 & 0.50 & 2.50 & 0.79 \\
\hline Hospital volume & & & & \\
\hline$\leq 75$ th percentile $(\leq 19 / \mathrm{yr})$ & Ref & & & \\
\hline$>75$ th percentile $(>19 / \mathrm{yr})$ & 0.62 & 0.30 & 1.30 & 0.20 \\
\hline Surgical characteristics & & & & \\
\hline Surgeon volume & & & & \\
\hline$\leq 75$ th percentile $(\leq 6 / \mathrm{yr})$ & Ref & & & \\
\hline$>75$ th percentile $(>6 / \mathrm{yr})$ & 1.74 & 0.88 & 3.41 & 0.11 \\
\hline Year of surgery & & & & \\
\hline 2003-2006 & Ref & & & \\
\hline 2007-2010 & 0.82 & 0.38 & 1.75 & 0.60 \\
\hline 2011-2015 & 0.88 & 0.39 & 1.97 & 0.76 \\
\hline
\end{tabular}


Supplementary Fig. 1A. Distribution of 991 surgeons in Premier Healthcare Database, who performed at least three percutaneous nephrolithotomy (PCNL) each year, ranked by average costs per surgery (with 95\% confidence intervals).

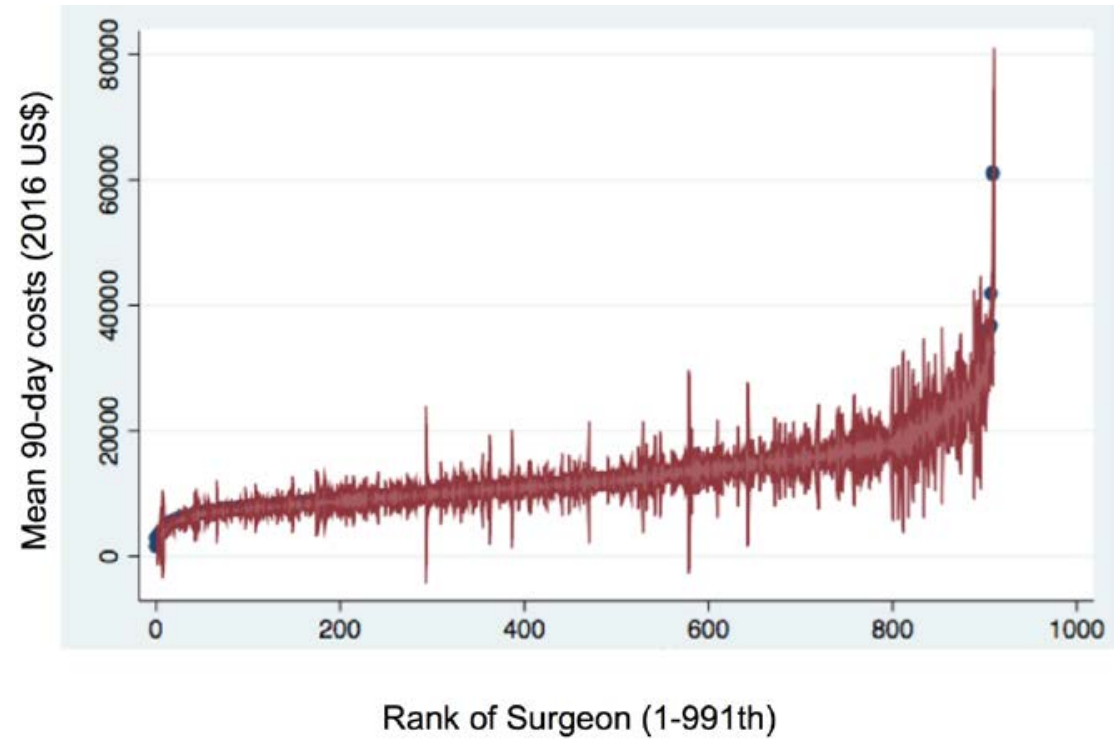

Supplementary Fig. 1B. Distribution of 301 hospitals in Premier Healthcare Database performing percutaneous nephrolithotomy (PCNL) each year, ranked by average costs per surgery and $95 \%$ confidence intervals.

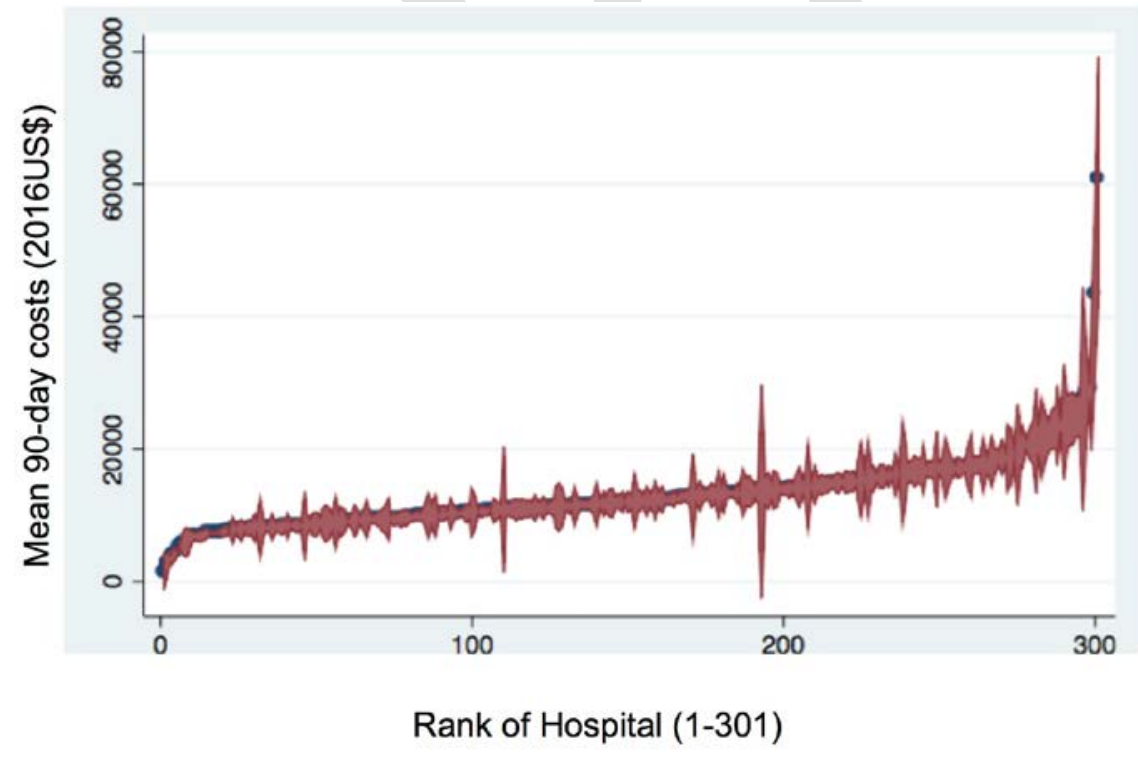


Supplementary Fig. 2. Trend in mean costs of percutaneous nephrolithotomy in the U.S. from 2003-2015.

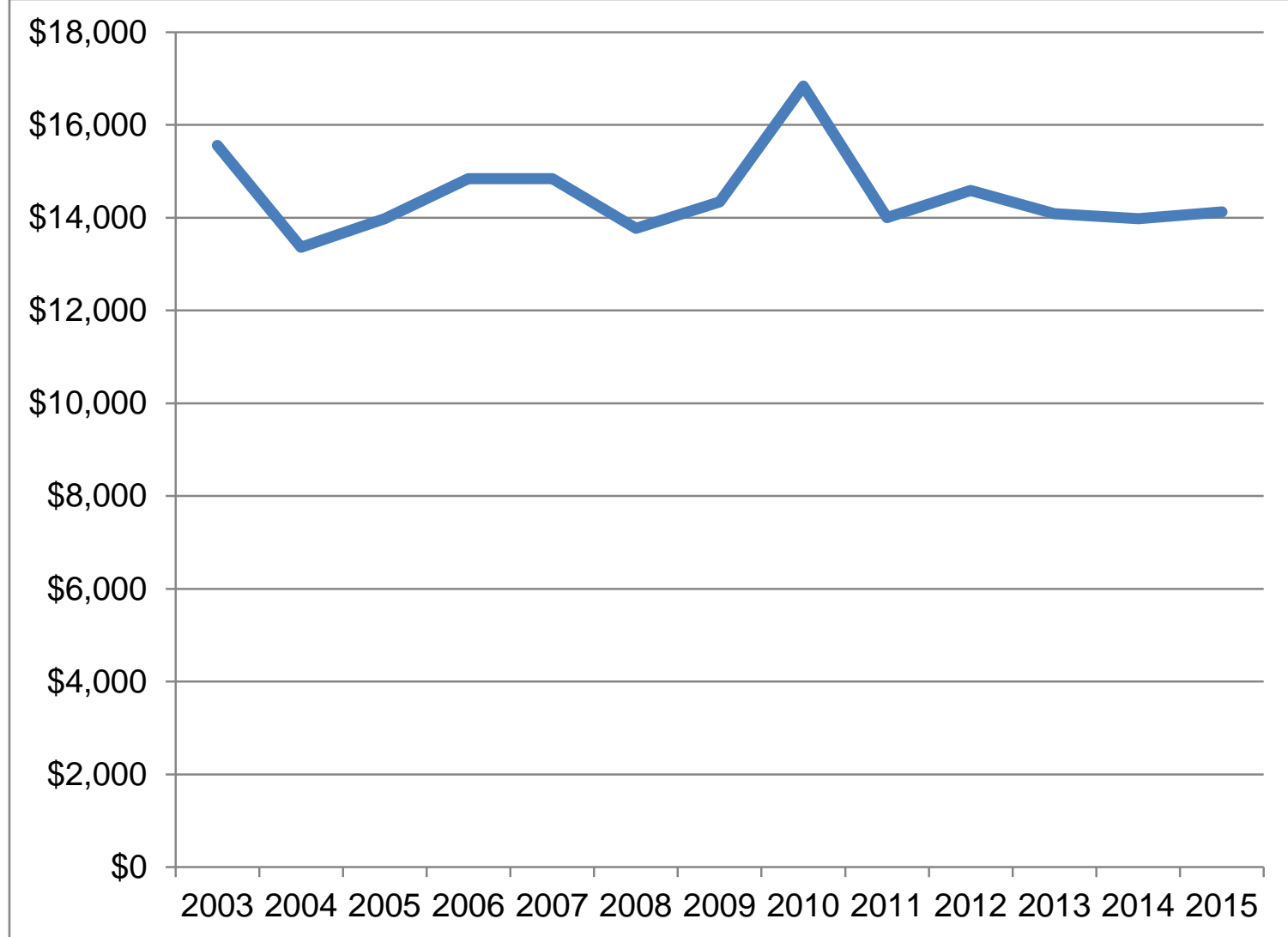

